\section{Intersections}

Canadian Journal of Music

Revue canadienne de musique
Intersections CANADIAN JOURAL OF MUSIC
REVUE CANADIENEE DE MUSIOUH

\title{
Ruth Crawford's String Quartet, Mvt. 3: An Analysis of Dynamic Counterpoint, Contour Similarity, and Musical Form
}

\section{Yi-Cheng Daniel Wu}

Volume 37, numéro 2, 2017

URI : https://id.erudit.org/iderudit/1066621ar

DOI : https://doi.org/10.7202/1066621ar

Aller au sommaire du numéro

\section{Éditeur(s)}

Canadian University Music Society / Société de musique des universités canadiennes

ISSN

1911-0146 (imprimé)

1918-512X (numérique)

Découvrir la revue

Citer cet article

Wu, Y.-C. D. (2017). Ruth Crawford's String Quartet, Mvt. 3: An Analysis of Dynamic Counterpoint, Contour Similarity, and Musical Form. Intersections, 37(2), 123-145. https://doi.org/10.7202/1066621ar
Résumé de l'article

Dans le troisième mouvement de son Quatuor à cordes, Ruth Crawford élabore localement un tissu contrapuntique dynamique singulier, dans lequel chaque instrument alterne différemment crescendo et diminuendo, les mêmes dynamiques ne se synchronisant ainsi jamais. Globalement, ce tissu contrapuntique dynamique projette une très longue expansion sonore graduelle allant de ppp à fff. De surcroit, Crawford met temporairement l'accent sur les deux dynamiques $f$ et $f f f$, divisant alors subtilement la forme en trois parties. Afin de soutenir cette subtile division formelle tripartite par Crawford, je traduis son contrepoint dynamique dans les termes d'une séquence chronologique de contours verticalisés, et en mesure la similarité. Je montre ainsi que les changements essentiels de la similarité des contours coïncident toujours avec les limites structurelles, précisant la division formelle de la conception schématique de Crawford.
Copyright @ C Canadian University Music Society / Société de musique des universités canadiennes, 2019
Ce document est protégé par la loi sur le droit d'auteur. L'utilisation des services d’Érudit (y compris la reproduction) est assujettie à sa politique d'utilisation que vous pouvez consulter en ligne.

https://apropos.erudit.org/fr/usagers/politique-dutilisation/ 


\title{
RUTH CRAWFORD'S STRING QUARTET, MVT. 3: AN ANALYSIS OF DYNAMIC COUNTERPOINT, CONTOUR SIMILARITY, AND MUSICAL FORM
}

\author{
Yi-Cheng Daniel Wu
}

\section{INTRODUCTION}

Figure 1 presents the formal outline in Ruth Crawford's String Quartet, Mvt. 3. It starts at the beginning and continues until three quarters of the way through the movement (mm. 1-76), where multiple sorts of the musical climaxes approximately meet and together create a strong sense of structural arrival point. If we look ahead at figure 5, these climaxes include the simultaneous registral peak and valley at $\mathrm{m} .75\left(\mathrm{E}_{6}\right.$ and $\left.\mathrm{C}_{2}\right)$, the arpeggiated harmony crossing a significant wide range of pitch space on each string on the downbeat of $\mathrm{m} .75$, the textural shift to a brief stretto at $\mathrm{m}$. 75 , and the most forceful dynamics $\mathrm{ff} z$ heavily punctuated by a staccato sign at $\mathrm{mm} .75-6 .{ }^{1}$ Among these climaxes, the dynamics is the most striking element, for not only is its arrival achieved through an extensively long gradual increase, three-part formal process of sound expansion from $p p p \rightarrow f(\mathrm{~mm} .1-43), f \rightarrow f f f(\mathrm{~mm} .44-66)$, to $f f f \rightarrow f f z$ $(\mathrm{mm} .67-76)$, this procedure is also stretched out by a unique musical fabric, where each instrument plays a different alternation of crescendo and diminuendo. In a letter to Varèse dated 6 April 1937, Crawford describes this texture as a "counterpoint of dynamics," where the "crescendi and diminuendi should be exactly timed, and no instrument should reach the high or low point at the same time as any other" (emphasis mine). ${ }^{2}$

This intertwined dynamic texture has inspired theorists proposing various methods to investigate it in relation to the three-part formal structure. Rao $(2007,126-8)$ approaches this issue by incorporating the change of dynamics along with the rhythmic durations. Rao calls the complete span of

1 To sharpen this climactic moment, Crawford uses simultaneous rests crossing all four strings and double barlines to separate all the previous part mm. 1-76 from the rest of the movement, $\mathrm{mm}$. 77-99. The bracketed Arabic numbers indicate the harmonic segmentations (the segmentation method will be explained fully later in the next section, "Background Setting"). After chord 37, the harmonies move faster as the intervals between them are much shorter, projecting another level that supports and prepares for the arrival of the integrated musical climaxes at the end of figure 5 .

2 Crawford's statement is cited in Gaume $(1987,204)$. In addition, Tick (1997, appendix A, 3578) presents Crawford's self-analysis of her arrangements of dynamics in this movement, including some facsimile reproductions of her musical examples. 


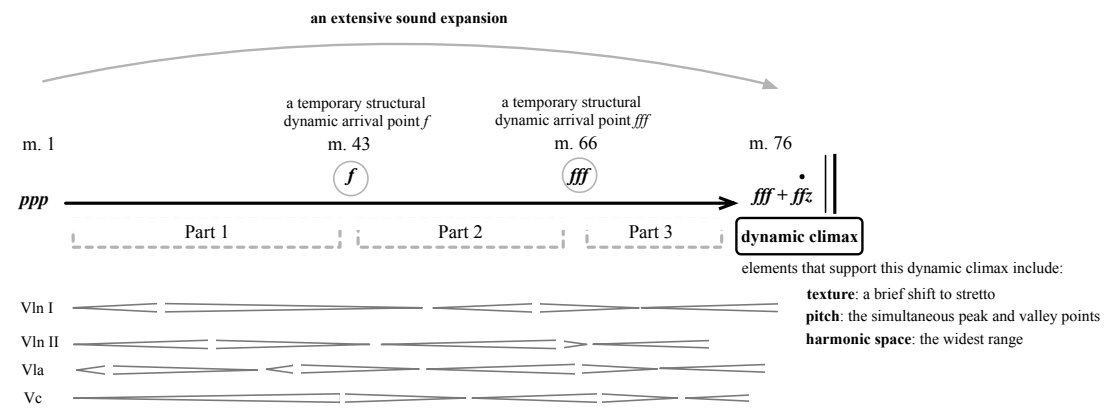

counterpoint of dynamics

Figure 1: Ruth Crawford, String Quartet, Mvt. 3; formal layout (mm. 1-76)

the crescendo-decrescendo process a dynamic slide. Each slide contains two integers: the duration of crescendo and that of decrescendo, creating a peak where the two meet. She categorizes three types of rhythmic slide that describe different shapes of slide: the mounting slide (the crescendo is longer than the decrescendo), the ebbing slide (the crescendo is shorter than the decrescendo), and the equilibrium slide (the crescendo and the decrescendo are equal). Her analysis finds that each of the three formal parts projects a distinctive rhythmic slide. Part 1 comprises mostly equilibrium slides, creating a "fairly balanced effect" (Rao 2007, 128) between the crescendo and decrescendo. The slides turn into the ebbing motions in Part 2, and this increases the "off-centeredness" (128) of the peak point that differentiates itself from the previous "stillness" (128) between the crescendo and decrescendo. Then the shapes of the slides change again to the mounting type, which contain a series of "shortened, hurried" decrescendos that build up a tension supporting the dynamic and registral climaxes in Part 3.

Another study focusing on the kinship between the arrangements of dynamics and duration can be found in an earlier publication by Nicholls (1990, 119-20), whose analysis shows a strong correlation with Rao's. Nicholls discovers that all of the entries of the complete crescendo-decrescendo processes (i.e., Rao's dynamic slides) are treated canonically among the four string instruments, and each formal part presents a particular pattern of the entries: Part 1: vla-vc-vln 2-vln 1; Part 2: various orders of canonic entries are introduced; and Part 3: vla-vln 2-vc-vln 1. Also emphasizing the instrumentations with regard to the dynamics, Straus $(1995,166-8)$ uses sequential integers o-3 to represent vc, vla, vln 2, and vln 1, respectively. He arranges these integers on the basis of when they reach their loudest points, forming a set called the firing order. For instance, $<1203>$ means that vla is the first to reach its loudest point, which is followed by vln 2, vc, and then vln 1 . Straus applies twelve-tone operations of prime, inversion, retrograde, and retrograde inversion to examine the relationships among the firing orders, and further analyzes how they can be associated with orders produced by other musical elements of pitch and duration in different parts of the form. 
Hisama (1995) complements work of the scholars above by focusing on less apparent climaxes narrated by pitch registers in this movement. Unlike the traditional standard string quartet setting, in which the four instruments from low to high project bass, tenor, alto, and soprano voices, the texture here is woven by intensive voice crossings. For instance, at time point $\mathrm{A}$ in figure 2, two voice crossings appear: vln 2 is higher than vln 1, and vc is higher than vla. Hisama calls such intertwined musical fabric a twisted texture, and she uses the term degree of twist to define the number of voice crossings. She finds multiple climaxes achieved by the gradual progressions moving toward and then away from such an exceedingly twisted texture, and they are always staggered with the arrival point of the dynamic climax at the end of each formal part outlined in figure 1. For Hisama, this highly twisted texture represents what she believes to be a "feminist" climax (305), which is opposed to the dynamics representing a more contextual, traditional, and "masculine" form of climax in a composition. ${ }^{3}$ Moreover, Gollin (2009) applies a Cayley graph to examine how the registral permutations of the four instruments create a transformational network that further supports Hisama's analysis of climaxes.

Gathered together in one view of all the discussions above, we have two complementary readings of formal articulations. Rao, Nicholls, and Straus take into account dynamics in relation to duration or instrumentation, and their analyses highlight the individual formal characteristic of each of the three parts. Hisama and Gollin deal with this movement by considering the pitch registers, and their findings indicate that the formal divisions defined by the dynamic climaxes do not coincide with those narrated by the highly twisted voice-crossing strands. In line with the first reading, this article concentrates on the details of the texture, applying my contour similarity measurement-the minimally divergent contour network-to translate Crawford's dynamic counterpoint into a chronological sequence of the verticalized dynamic contour segments (dcsegs) and study their relationships. When I describe my methodology in two of my own works $(2012,2013)$, the terms vary from my dissertation to the later publication, but their basic concept remains the same. To consistently describe the theory in this article, I use the terms from the more recent publication (2013). Similar to Straus's firing order, a dcseg is a set describing the simultaneous dynamics among the four instruments at a particular time point. However, unlike the firing order, the elements within a dcseg will be fully set on a fixed arrangement of instruments in the quartet from the lowest to the highest strings. My findings suggest a strong analytical echo with the results proposed by Rao and Nicholls, for every formal part unfolds a distinctive formal characteristic. That is, dcsegs in Parts 1 and 3 are closely located at the centre of the contour network, sharing great resemblance of their dynamic shapes. Contrarily, dcsegs in Part 2 navigate outward from the network's centre, becoming less similar in their contours. These geographically close versus distant locations and high versus low contour similarities among

3 Hisama's 1995 article is also included in Hisma (2001, chapter 2, 12-34). In the latter publication she presents chapters 3 and 4 on detailed analyses of Crawford's music in relation to gender. 


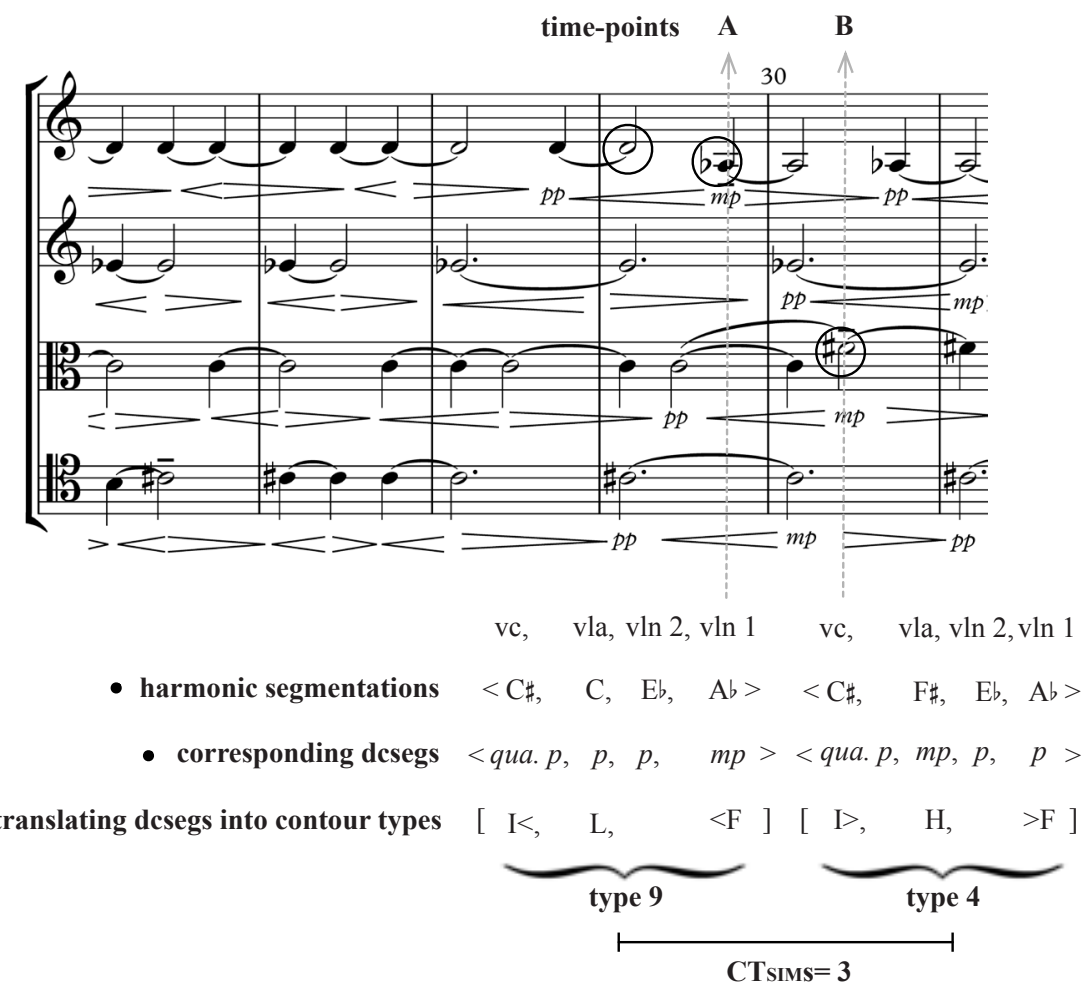

Figure 2. Ruth Crawford, String Quartet, Mvt. 3, mm. 26-31; dynamic contour segments (dsegs).

dcsegs in the network serve as a crucial reference to deepen and strengthen the formal divisions articulated by the arrivals of - to borrow Hisama's term-the "masculine form" of the dynamic climaxes in Crawford's three-part schematic design.

\section{Background Setting: Dcsegs and Contour Similarity MeASUREMENT}

This section prepares the reader for some necessary background knowledge of my method of dynamic contour segmentations and the measurement of testing their similarities (see figure 2). I follow the flow of harmonies to segment a dcseg. In Mvt. 3, each instrument plays a single and different note. A succession of four simultaneous pitches creates a series of tetrachordal progression. The adjacent tetrachords differ from one another by the movement of a single pitch, while the remaining ones stay fixed. ${ }^{4}$ For instance, at time-point $\mathrm{A}$, the first violin's $\mathrm{A}-\mathrm{b}_{3}$ is proceeded by $\mathrm{D}_{4}$ while the remaining three instruments still

4 Connecting these moving pitches forms what Straus refers to as the "main melody" $(1995,161)$. Straus has thoroughly analyzed this main melody for its pitch-class structure, patterns of instrumentation, and relationship between pitch and duration contours (158-64). 


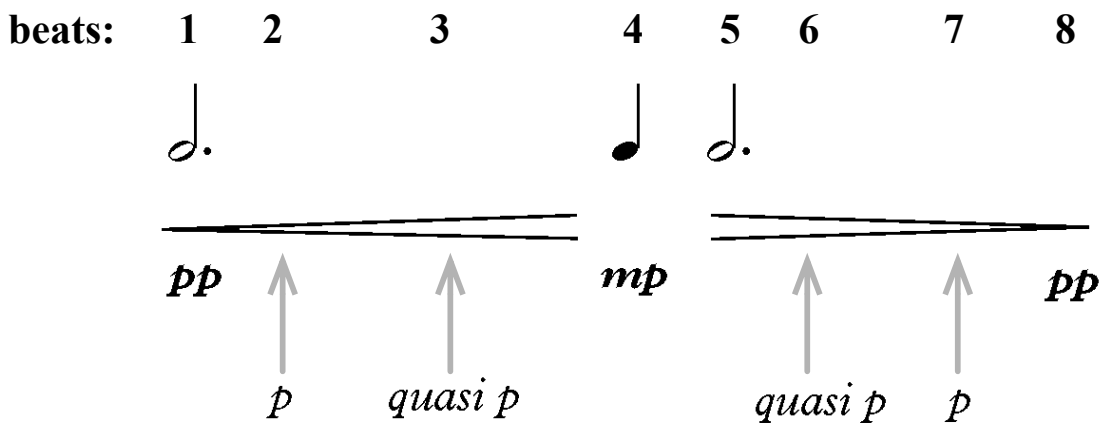

Figure 3: Subdivide the dynamics between $m p$ and $p p$ in figure 2.

play the same notes. This creates a tetrachord $<\mathrm{C}-\sharp, \mathrm{C}, \mathrm{E}-\mathrm{b}, \mathrm{A}-\mathrm{b}\rangle$ (always read from the lowest to the highest instruments). Time-point $\mathrm{B}$ forms another tetrachord because the pitch $\mathrm{C}_{4}$ moves to $\mathrm{F}-\sharp_{4}$ in the viola at $\mathrm{m}$. 30 . The formation of a dcseg cleanly coincides with a harmonic time-point, embracing different levels of contrapuntal dynamics associated with their corresponding pitches. This type of verticalized dcseg segmentation reflects a particular dynamic, timbral package articulating the change of a new chord (as opposed to a beat-to-beat type of dcseg segmentation). The crescendo and diminuendo travel between $m p$ and $p p$ within the total span of seven beats (mm. 28-31, starting from vln 2 , vln 1 , vc, and vla). To more accurately measure the dynamics associated with its time-point, figure 3 subdivides two more dynamics $p$ and quasi $p$ between $p p$ and $m p$, thus each beat receives a particular dynamic assignment. Based on this subdivision, I derive dcsegs $<q u a s i p, p, p, m p>$ at time-point $\mathrm{A}$ and $<q u a s i$ $p, m p, p, p>$ at time-point $\mathrm{B}$ in figure 2 .

Here the reader may find that the definition of a musical contour in figure 2 essentially deviates from a more conventional definition in two aspects. First, the dynamics that create a dcseg are not linearly, sequentially spread out in time. Rather, they are vertically aligned at one particular time-point. Generally, in the field of contour theory, pitch contour is the most popular subject of study, and theorists commonly define a pitch contour on the basis of two sequential dimensions - contour space (from low to high) and sequential time (from the first to the last). I refer to this perception of contour as linear contour. Importantly, a linear contour can be further extended to describe and trace the horizontal flow of a musical figure narrated by elements other than pitch-such as duration (short versus long). 5 Contrary to the linear contour, the dcseg in this article describes a contour in a vertical axis, expressing Crawford's contrapuntal texture in terms of an ordered set composed of the four aligned, simultaneous dynamic marks. I refer to this perception of a contour

5 Studies that deal with the linear contour can be found in Friedmann $(1985,1987)$, Marvin and Laprade (1987), Morris (1987, 1993), Marvin (1989, 1991, 1995), Quinn (1997, 1999), Schmuckler (1999, 2010), Shmulevich (2004), Carson (2004-5), Schultz (2008, 2009, 2016), Bor (2009), Pearsall (2012), and Carter-Ényí (2016), among others. 
as the vertical contour. Importantly, since the study of the vertical contour is less common than that of the linear, it is necessary to offer supplementary information on how other theorists define and construct different types of vertical contour that are essentially different from my own work. The reader thus can have a more comprehensive understanding of the formation of a vertical contour crossing various contexts of musical analyses. Besides dynamics, in the current analytical literature the most common element that theorists take into account to create a vertical contour is the harmonic space. For instance, if we define a chord as a collection of harmonic intervals formed by each pair of adjacent pitches, then its contour can be described vertically through the comparison of the sizes of its constituent intervals as being more compact, spatial, or equal to one another. ${ }^{6}$

Second, the dynamics in a dcseg is arranged not according to the pitch height from the lowest to the highest, but consistently to the instrumental setting of a string quartet from vc, vla, vln 2, to vln 1 . The reason has to do with a particular musical fabric created by the intensive voice crossings in this quartet mentioned in the introduction. Such an intricate texture woven by the highly interlaced melodic threads cannot project the traditional standard string quartet setting, in which the four instruments from low to high project bass, tenor, alto, and soprano voices. If we were to arrange the dynamics on the basis of the actual pitch heights, we would have derived a succession of dcsegs whose dynamics always shift places from their original positions located below their corresponding instruments on the score, breaking down the strict contrapuntal texture orchestrated by the setting of a string quartet. Prompted by this issue of inconsistency caused by the frequent voice crossings, I have decided to arrange the dynamics in a dcseg consistently based on the instrumentation. The resultant dcsegs can thus be best thought of as a suggestive way to comprehend the quartet's surface texture that is exceedingly twisted, while grounding its counterpoint of dynamics on a footing of the fixed instrumentation.

Next, I apply my minimally divergent contour network to translate dcsegs into my contour notation and then compare the similarity between them. I refer to the resultant degree of resemblance between two contour types as the

6 Representative works that consider the vertical contour created by harmonic space include Marvin (1995), Hermann (1995), Klein (1999), Straus (2005), and my own work (2016), among others. Note that although Klein and Straus do not explicitly point out the keyword contour in their articles, their analytical outcome nevertheless expressing the overall shift in chordal space implies a strong sense of harmonic contour.

For a more tangible and detailed image of a construction of this type of vertical contour, see the works of the following four scholars. Marvin's pitch-span contours (1995, 162-71) describe the space between each pair of the adjacent pitches within a chord in Stockhausen's Klavierstücke, Nr. 2/I. Hermann studies the way harmonies transform their chordal density from their original referential chords through nine different chordal shape functions (1995, 377-9; he also calls them "contour functions" in 377n15) in Berio's Sequenza IV for Piano. Klein's compression of a harmonic aggregate describes "how tightly packed the voices are within a [chord]" $(1999,44)$ in Lutosławski's late music. Straus extends his offset number derived from his fuzzy transformational voice leading (2005, particularly 73-83) to examine the degree of chromaticness of a chord.

In my own work (2016), I reconsider the space of all ics o-6 and propose a measurement called the average transformed voice pair interval class set to examine the density of post-tonal harmonies. 
contour type similarity-C $\mathrm{CT}_{S I M} .^{7}$ The strengths of adopting this approach are that (1) it allows us to perceive the contour similarity in terms of a more concrete visual representation of the geographical close/distant locations within the network, and (2), as shown later in my findings, the mappings of different dynamic contour types can be used as a crucial reference to support and articulate the formal divisions among the three parts in this movement. Before moving on, I need to explain the formation and methodology of my network (see figure 4). ${ }^{8}$ There are fifteen circles identified by numbers $1-15$ in the network. Each contains a set representing a particular pitch contour type outlining the overall melodic shape articulated by the four boundary contour pitches (cps): Initial, Final, Highest, and Lowest. 9 Two additional symbols " $>,<$ " are used to further clarify the relationship between cps [I, F]..$^{10}$ The arrows always point to a lower $\mathrm{cp}$. For instance, $[\mathrm{I}>,>\mathrm{F}]$ means $\mathrm{cp} \mathrm{I}$ is higher than $\mathrm{cp} \mathrm{F}$, while $\mathrm{cp} \mathrm{F}$ is higher than $\mathrm{cp} I$ in the situation of $[\mathrm{I}<,<\mathrm{F}]$. If two arrows point to each other, that means cps I and $\mathrm{F}$ are level (i.e., $[\mathrm{I}>,<\mathrm{F}])$. A line connects any two types if there is one different or extra cp in between. ${ }^{11}$ For instance, the bottom of figure 4 compares two pairs of types, and each pair is linked by one line in the network. Type 8 has one different $\mathrm{cp}$ I> from type 9 or vice versa, and type 11 has one more cp L than type 5. Within this network, we can efficiently and easily test the degree of similarity by measuring the shortest distance-more specifically, the fewest lines on the path-between any two contour types. The distance may range from o to 4 steps: from two utterly identical to two drastically different types. In other words, the greater value the $\mathrm{CT}_{\text {SIM }}$, the less similar

7 I actually call my measurement contour similarity of Adams's type-CSIM-AT $(2013,12)$. The term Adams's type refers to Charles Adams's contour typology (1976), which provides the methodological source reference for me to develop my contour network. In this article, I use a visually simpler and more concise nomenclature to describe the contour similarity-CTSIM (contour type similarity).

8 For details about my methodology, see $\mathrm{Wu}(2013,8-37)$.

9 Note that none of the contour types can accommodate non-adjacent repeated cps. For instance, if we have a segment [I>, H, L, H, >F], it cannot be categorized into any of the fifteen types. To address such issue, please see my own work (2019).

10 Note that all the contour types in figure 4 are ordered set. Traditionally we use " $<$ " to notate an ordered set. But this notation may create a visual confusion with the arrows of "> " and "<." To avoid this confusion, I use square brackets "[ ]" to represent a contour type throughout this article.

11 In other words, within this network, any two contour types that are one line apart are always $\mathrm{CT}_{\text {SIM }}$ 1-related. Additionally, in my dissertation $(2012,137)$, I suggest that this network seemingly recaptures the sense of smoothness described in Cohn (1996). Cohn's theory groups six chromatic triads to create a maximally smooth cycle, in which each pair of the adjacent triads share two common tones, while the remaining ones are consistently related by one semitone apart. My network features the same consistency as Cohn's maximally smooth cycle, because one move in the contour network corresponds to one altered cp from one type to another. Also, in a conversation with Philip Stoecker, he pointed out to me that my smoothness can be also arguably related to Straus's "parsimonious voice-leading space for set-classes" $(2005,50)$. Straus uses his fuzzy transformation and offset number to examine voice leading between two chords in terms of their set-class (sc) representatives. In his figure 4 entitled "parsimonious voice-leading space for trichord class" (52), Straus pairs any two trichordal scs related by offset number 1 and then uses a line to connect them. This also results in a network, in which one move in this sc-space equals one parsimonious move in offset number 1 from a sc to another (for more information about Straus's fuzzy transformational voice leading, also see his 1997 and 2003). To conclude, we experience the concept of smoothness (and parsimony) crossing three different areas from Cohn's voice leading in chromatic triads, to Straus's voice leading in sc-space, and to my pitch contour. 


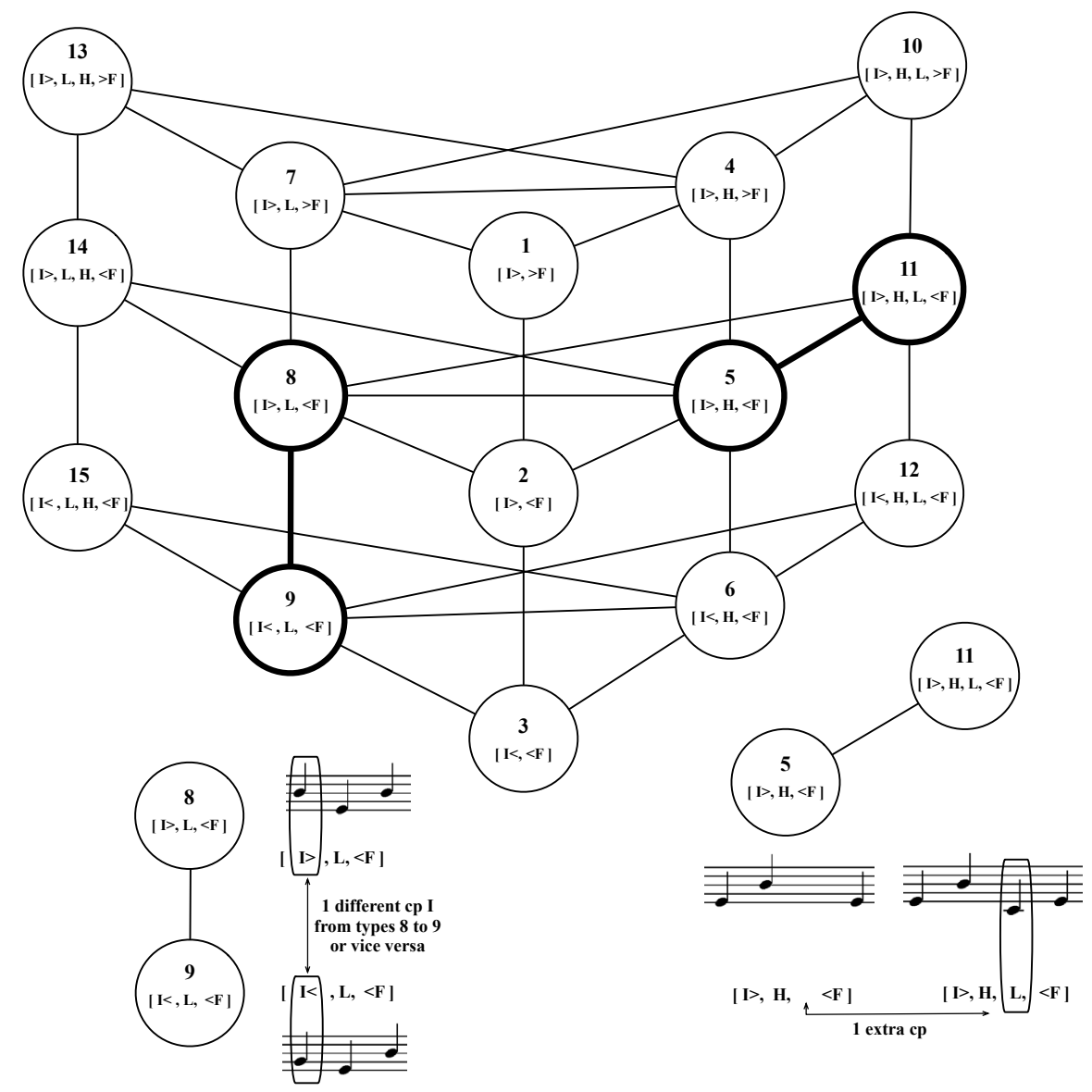

Figure 4: The minimally divergent contour network.

the two contour types. Importantly, the limited range of $\mathrm{CT}_{\text {SIM }}$ from o to 4 allows us to tangibly define the relationship among all the dcsegs in this quartet, obtaining a more concrete sense of similarity relations with regard to their identical, alike, or different dynamic sound images.

In my analysis, I slightly modify the meanings of my cps I, F, H, and L, extending them from the original description of pitch heights to that of dynamic levels. That is, cps I and F respectively delineate the beginning and ending dynamics; in this case they are respectively produced by the two outer instruments of vc and vln 1 . And cps $\mathrm{H}$ and $\mathrm{L}$ are the dynamics (if any) deviating from cps I and F, representing the strongest and weakest volume associated with the inner two instruments of vla and vln 2. For instance, the dcseg <quasi $p, p, p, m p>$ at time-point $\mathrm{A}$ in figure 2 corresponds to type $9[\mathrm{I}<, \mathrm{L},<\mathrm{F}],{ }^{12}$ while 
dcseg <quasi p, mp, p, p> at time-point B forms type $4[\mathrm{I}>, \mathrm{H},>\mathrm{F}] .{ }^{13}$ If we locate these two types in the network in figure 4 , the shortest distance between them takes three steps. Thus, their $\mathrm{CT}_{\text {SIM }}$ is equal to $3 \cdot{ }^{14}$

\section{Analysis}

Figure 5 presents an annotated score, which shows the formal divisions of the three parts and sixty-three dcsegs. Part 1 contains dcsegs (1)-(27); (28)-(53) are in Part 2; and the remaining (54)-(63) can be found in Part 3. The musical climax at the end is achieved by both dynamics and register, approximately in the area framed by dcsegs (61)-(63). At dcseg (61), the music reaches to the highest (vln 1) and lowest registers (vc) supported by the strongest dynamics fff with an additional accent mark " $\wedge$." Although the lowest register (vc) rapidly climbs up to the higher range of the register at dcseg (63), dynamically the music proceeds to the most powerful sound in figure 5- fff heavily punctuated by an additional accent mark $f f z{ }^{15}$ On the score, the dynamic terms include (from the weakest to the strongest) $p p p, p p, p, m p, m f, f$, ff, fff. To more accurately describe the dynamic counterpoints among the four simultaneous string instruments, similar to the previous subdivisions in figure 3, figure 6 adds four more dynamics quasi p, quasi $f$, quasiff, and quasi fff based on the contextual needs. Table 1 lists all the dcsegs, ${ }^{16}$ the translation of my nomenclatures, and their associated contour types.

Figure 7 analyzes the mappings of contour types in Part 1. For the sake of clearer discussion, here and the following two figures divide the network into three zones A, B, and C, according to their geographical distance close to or far from the centre of the network. Importantly, the relative distance to the network's centre will allow us to musically reflect the level of contour elaboration from a broader scope. A-zone is the axis running through the centre of the network, which contains types 1-3 with no deviated cp. I call this zone the central area. Types in this area project the direct figures - a horizontal line (type 2) and two inversionally related contours of ascending (type 3 ) and descending slopes (type 1). They provide the source, original models from which the remaining

13 Like the previous dcseg, here we also see vln 2 and vln 1 play the same dynamics $p$. I consider vln 1 because it represents the ending dynamics.

14 Complementary to my contour types, studies that also deal with the subject of contour typology can be found in Seeger (1960), Adams (1976), and Morris (1993). For detailed discussion and critique of their typologies, see $\mathrm{Wu}(2012,14-28)$.

15 Right after the quartet passes dcseg (60), Crawford marks sempre fff on the score. Thus, the remaining three dcsegs (61)-(63) all appear within the realm of fff. The differences among them is the level of the extra accent emphasis by either " $\wedge$ " or " $f f z$."

16 Table 1 provides the analyst with a new possibility of chordal segmentation based on the change of dynamics. It also lends him/her a crucial reference to logically associate certain chords together for they share the same arrangement of the dynamics (for instance, we can relate dcseg (48) to (53) in Part 2, because they all project the same type of dynamic contour [I >, L, H, >F]). Aside from the dynamics discussed in this paper, the most common associational approach appears in pitch-class set theory. For instance, scholars focus on the kinships among consecutive or non-consecutive pitchclass segments that can be associated by a certain underlying attribute (such as the same set-class family member, pitch contour, or an apparent contextual element). The representative research of the association theory includes Straus (1987), Hannien (1996, 2004, 2012), and Mailman (2015). 

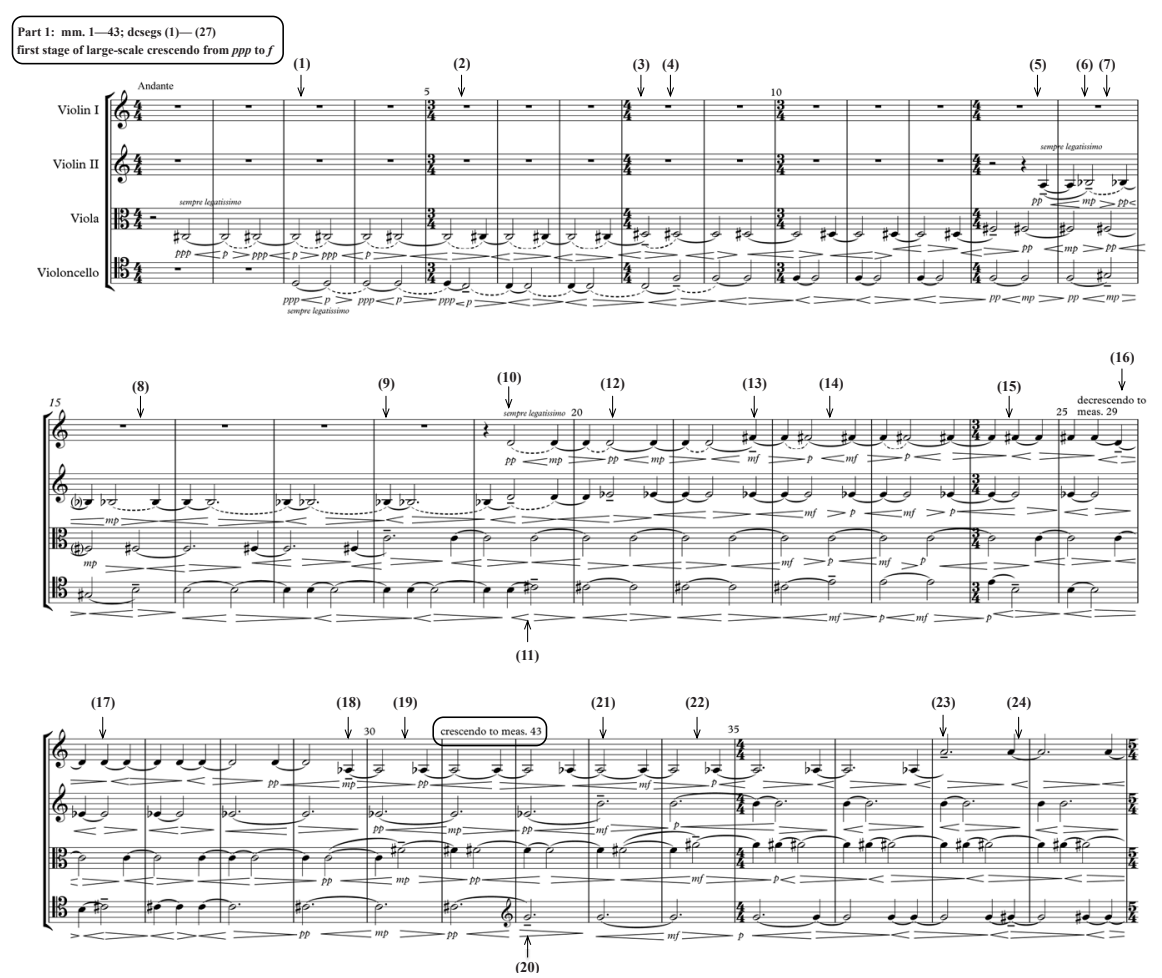

Figure 5. Crawford, String Quartet, Mvt. 3, mm. 1-76; dcseg segmentations.

contour types in the network may spring. As the contours move outward from the centre, they transform into more and more elaborated and complex figures. B-zones slightly move away from the both sides of the central axis, including types 4-6 and 7-9 that have one deviated cp. I refer to the types in B-zones as the moderately elaborated contours. C-zones are located at both far edges of the network, including types 10-12 and 13-15 with two deviated cps, forming the fully elaborated contours. In my analysis, besides $\mathrm{CT}_{\mathrm{SIM}} \mathrm{S}$, I also distinguish the character of each formal part in terms of its general dynamic texture created by the level of contour elaboration. The more elaborated the contours, the more intricate the dynamic texture; contrarily, the more direct the contours, the simpler the texture.

The quartet begins with six dcsegs wandering between types 1 and 3 (see table 2). These two contour types are located at the central area, mapping to each other via a two-step move $\left(\mathrm{CT}_{\mathrm{SIM}}=2\right.$, marked by bold, solid lines in figure 7) by passing through the network's centremost type 2. Importantly, although type 2 does not occur in Part 1, it does come on the scene at the very end of Part 3 , which-along with the registral and dynamic climaxes-closes my selected passage (mm. 1-76). After the initial six dcsegs, the quartet progresses to the core of Part 1, which contains the remaining dcsegs (7)-(27), mostly projecting types 1,4 , and 7 , with some occasional occurrences of types 9 and 3 (see table 2). In figure 7 , types 1,4 , and 7 are intimately related, creating a small, solid 

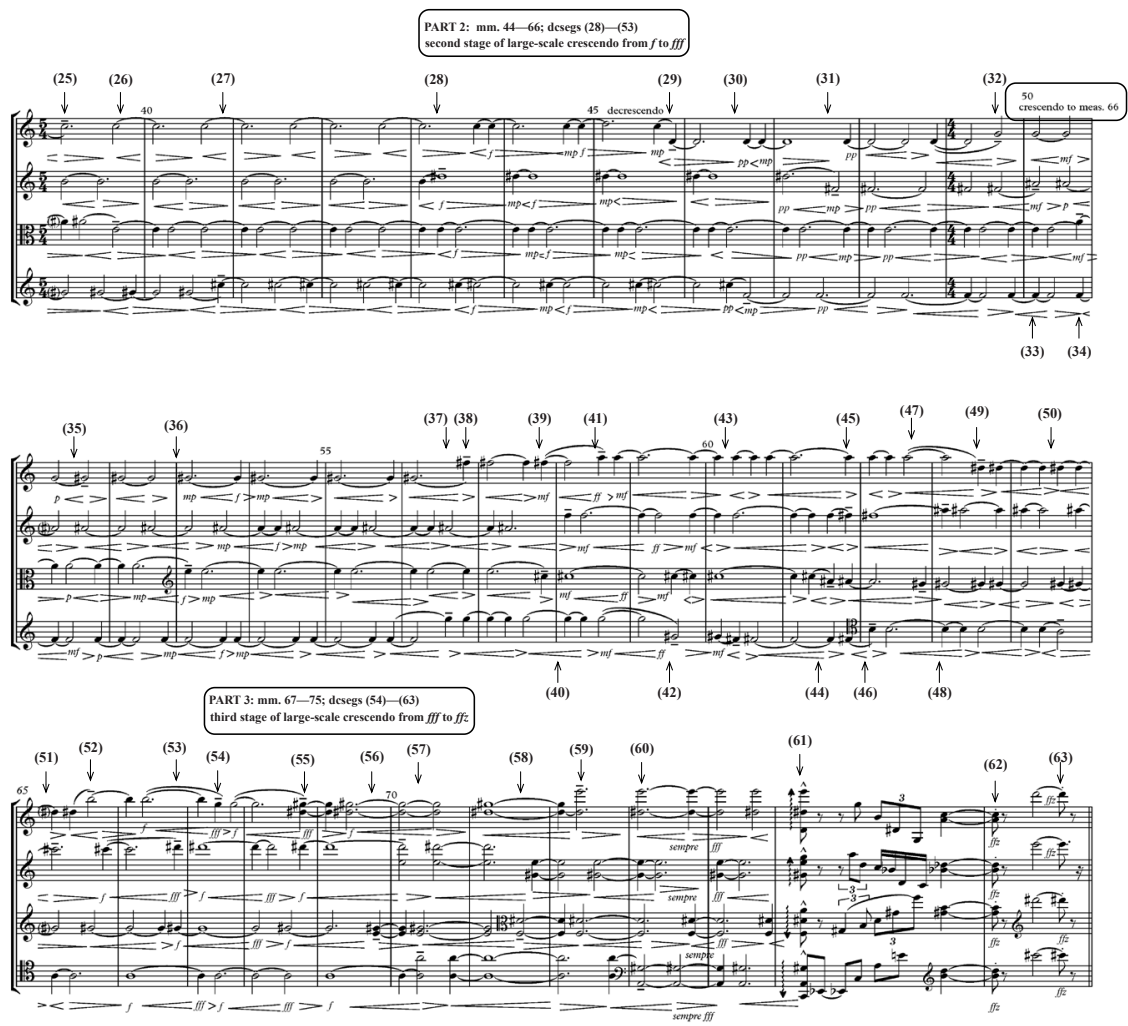

Figure 5 (PART 2).

ppp $\quad p p \quad p \quad$ quasi $p \quad m p \quad m f$ quasif $f$ quasiff $f f$ quasifff $f f f$

Figure 6. Subdivide the dynamics from $p p p$ to $f f f$.

triangle in the upper centre of the network. They consistently map to one another by a one-step move in this network space $\left(\mathrm{CT}_{\mathrm{SIM}}=1\right.$; see bold, dashed lines in the network), showing a strong similarity relation among them-they all have the same flanking cps $[\mathrm{I}>,>\mathrm{F}]$, and the only difference is whether or not they have one deviated $c p$ in the middle. Also, I must point out a unique feature essentially distinguishing Part 1 from the other two parts. It contains many immediate repetitive types-for instance, dcseg (5) repeats (4)'s type 1; both (7) and (8) project a type 7; and so forth. These immediate repetitive types remain stationary in the network, resulting in a $\mathrm{CT}_{\text {SIM }}$ o. To conclude, geographically all dcsegs in Part 1 appear within or near the central area of the network, projecting either direct or moderately elaborated contours that create a simple dynamic texture. They start with a few types mapping along the line with the axis via either $\mathrm{CT}_{\text {SIM }} \mathrm{O}$ or 2 and then moving to the core containing types located in the upper centre triangle with either $\mathrm{CT}_{\mathrm{SIM}} \mathrm{O}$ or 1 apart.

As soon as the quartet enters Part 2, the mapping instantly expands outward to C-zone on the left edge of the network (see figure 8). According to table 3, all 
Table 1. Dcsegs, dynamic counterpoint, and their corresponding contour types.

\begin{tabular}{|c|c|c|c|c|c|c|c|}
\hline Part & dcseg \# & $<\mathrm{Vc}$ & Vla, & $V \ln 2$, & Vln $1>$ & Translation & Type \\
\hline \multirow{27}{*}{ Part 1} & (1) & $p p p$ & $p$ & & & {$[\mathrm{I}<,<\mathrm{F}]$} & 3 \\
\hline & $(2)$ & $p$ & $p p$ & & & {$[\mathrm{I}>,>\mathrm{F}]$} & 1 \\
\hline & (3) & $p p p$ & $p$ & & & {$[\mathrm{I}<,<\mathrm{F}]$} & 3 \\
\hline & (4) & $p$ & $p p p$ & & & {$[\mathrm{I}>,>\mathrm{F}]$} & 1 \\
\hline & (5) & $p$ & $p$ & $p p$ & & {$[\mathrm{I}>,>\mathrm{F}]$} & 1 \\
\hline & (6) & $p$ & $p$ & $m p$ & & {$[\mathrm{I}<,<\mathrm{F}]$} & 3 \\
\hline & (7) & $m p$ & $p p$ & $p$ & & {$[\mathrm{I}>, \mathrm{L},>\mathrm{F}]$} & 7 \\
\hline & (8) & $m p$ & $p p$ & $p$ & & {$[\mathrm{I}>, \mathrm{L},>\mathrm{F}]$} & 7 \\
\hline & (9) & $p$ & $m p$ & $p p$ & & {$[\mathrm{I}>, \mathrm{H},>\mathrm{F}]$} & 4 \\
\hline & (10) & $m p$ & $p$ & $m p$ & $p p$ & {$[\mathrm{I}>,>\mathrm{F}]$} & 1 \\
\hline & (11) & $m p$ & $p p$ & $p$ & $p$ & {$[\mathrm{I}>, \mathrm{L},>\mathrm{F}]$} & 7 \\
\hline & (12) & $p$ & $p$ & $m p$ & $p p$ & {$[\mathrm{I}>, \mathrm{H},>\mathrm{F}]$} & 4 \\
\hline & (13) & $p$ & quasi $p$ & $p p$ & $m f$ & {$[\mathrm{I}<, \mathrm{L},<\mathrm{F}]$} & 9 \\
\hline & (14) & $m f$ & $p$ & $m p$ & $m p$ & {$[\mathrm{I}>, \mathrm{L},>\mathrm{F}]$} & 7 \\
\hline & (15) & $m f$ & $m p$ & $m f$ & $p$ & {$[\mathrm{I}>,>\mathrm{F}]$} & 1 \\
\hline & (16) & $m p$ & $p$ & $m p$ & $m f$ & {$[\mathrm{I}<, \mathrm{L},<\mathrm{F}]$} & 9 \\
\hline & (17) & $m f$ & $m p$ & $m f$ & $p$ & {$[\mathrm{I}>,>\mathrm{F}]$} & 1 \\
\hline & (18) & quasi $p$ & $p$ & $p$ & $m p$ & {$[\mathrm{I}<, \mathrm{L},<\mathrm{F}]$} & 9 \\
\hline & (19) & quasi $p$ & $m p$ & $p$ & $p$ & {$[\mathrm{I}>, \mathrm{H},>\mathrm{F}]$} & 4 \\
\hline & $(20)$ & $m p$ & quasi $p$ & $p p$ & $p$ & {$[\mathrm{I}>, \mathrm{L},>\mathrm{F}]$} & 7 \\
\hline & (21) & $p p$ & $p$ & $m f$ & $p$ & {$[\mathrm{I}>, \mathrm{H},>\mathrm{F}]$} & 4 \\
\hline & $(22)$ & $m p$ & $m f$ & quasi $p$ & quasi $p$ & {$[\mathrm{I}>, \mathrm{H},>\mathrm{F}]$} & 4 \\
\hline & (23) & $p$ & quasi $p$ & $p$ & $m f$ & {$[\mathrm{I}<,<\mathrm{F}]$} & 3 \\
\hline & (24) & $m f$ & $m p$ & quasi $p$ & $p$ & {$[\mathrm{I}>,>\mathrm{F}]$} & 1 \\
\hline & (25) & $m p$ & quasi $p$ & $p$ & $m f$ & {$[\mathrm{I}<, \mathrm{L},<\mathrm{F}]$} & 9 \\
\hline & (26) & quasi $p$ & $m f$ & $m p$ & $p$ & {$[\mathrm{I}>, \mathrm{H},>\mathrm{F}]$} & 4 \\
\hline & (27) & $m f$ & $m p$ & quasi $p$ & quasi $p$ & {$[\mathrm{I}>,>\mathrm{F}]$} & 1 \\
\hline \multirow{13}{*}{ Part 2} & (28) & quasi $p$ & $p$ & $f$ & $m p$ & {$[\mathrm{I}<, \mathrm{L}, \mathrm{H},<\mathrm{F}]$} & 15 \\
\hline & (29) & quasif & $m f$ & $m p$ & $f$ & {$[\mathrm{I}<, \mathrm{L},<\mathrm{F}]$} & 9 \\
\hline & (30) & $m p$ & quasif & $m p$ & $p p$ & {$[\mathrm{I}<, \mathrm{H},<\mathrm{F}]$} & 6 \\
\hline & (31) & $p$ & quasi $p$ & $m p$ & $p$ & {$[\mathrm{I}>, \mathrm{H},<\mathrm{F}]$} & 5 \\
\hline & (32) & $p$ & $p$ & $p p$ & $m p$ & {$[\mathrm{I}<, \mathrm{L},<\mathrm{F}]$} & 9 \\
\hline & (33) & $p$ & quasi $p$ & $m f$ & $p p$ & {$[\mathrm{I}>, \mathrm{H},>\mathrm{F}]$} & 4 \\
\hline & (34) & $p p$ & $m f$ & quasi $p$ & $m p$ & {$[\mathrm{I}<, \mathrm{H},<\mathrm{F}]$} & 6 \\
\hline & (35) & $m p$ & quasi $p$ & $p$ & $m f$ & {$[\mathrm{I}<, \mathrm{L},<\mathrm{F}]$} & 9 \\
\hline & (36) & $m f$ & $f$ & quasif & $m p$ & {$[\mathrm{I}>, \mathrm{H},>\mathrm{F}]$} & 4 \\
\hline & (37) & $f$ & quasif & $m p$ & quasif & {$[\mathrm{I}>, \mathrm{L},>\mathrm{F}]$} & 7 \\
\hline & (38) & $m p$ & $f$ & $m f$ & $f$ & {$[\mathrm{I}<,<\mathrm{F}]$} & 3 \\
\hline & (39) & $m f$ & $f$ & quasif & $m f$ & {$[\mathrm{I}>, \mathrm{H},<\mathrm{F}]$} & 5 \\
\hline & (40) & quasif & $m f$ & $f$ & quasif & {$[\mathrm{I}>, \mathrm{L}, \mathrm{H},<\mathrm{F}]$} & 14 \\
\hline
\end{tabular}


Table 1 (cont'd)

\begin{tabular}{|c|c|c|c|c|c|c|c|}
\hline \multirow{13}{*}{ Part 2} & (41) & $m f$ & $f$ & quasif & $f f$ & {$[\mathrm{I}<,<\mathrm{F}]$} & 3 \\
\hline & (42) & $f f$ & $m f$ & $f$ & quasif & {$[\mathrm{I}>, \mathrm{L},>\mathrm{F}]$} & 7 \\
\hline & (43) & $f f$ & quasif & $m f$ & $m f$ & {$[\mathrm{I}>,>\mathrm{F}]$} & 1 \\
\hline & (44) & $f f$ & $f f$ & $m f$ & $f$ & {$[\mathrm{I}>, \mathrm{L},>\mathrm{F}]$} & 7 \\
\hline & (45) & $m f$ & $m f$ & $f f$ & $f f$ & {$[\mathrm{I}<,<\mathrm{F}]$} & 3 \\
\hline & $(46)$ & $f f$ & quasif & $m f$ & $m f$ & {$[\mathrm{I}>,>\mathrm{F}]$} & 1 \\
\hline & $\begin{array}{l}(47) \\
\end{array}$ & quasif & $f f$ & $f$ & quasif & {$[\mathrm{I}>, \mathrm{H},<\mathrm{F}]$} & 5 \\
\hline & (48) & $f$ & $m f$ & $f f$ & quasif & {$[\mathrm{I}>, \mathrm{L}, \mathrm{H},>\mathrm{F}]$} & 13 \\
\hline & (49) & $m f$ & $f$ & quasif & $f f$ & {$[\mathrm{I}<,<\mathrm{F}]$} & 3 \\
\hline & $\begin{array}{l}(50) \\
\end{array}$ & $f f$ & $m f$ & quasif & $m f$ & {$[\mathrm{I}>,>\mathrm{F}]$} & 1 \\
\hline & (51) & $m f$ & $f$ & $f f$ & $f f$ & {$[\mathrm{I}<,<\mathrm{F}]$} & 3 \\
\hline & $(52)$ & $f$ & $m f$ & quasif & $f f$ & {$[\mathrm{I}<, \mathrm{L},<\mathrm{F}]$} & 9 \\
\hline & $\begin{array}{l}(53) \\
\end{array}$ & quasifff & $f$ & $f f f$ & $f f$ & {$[\mathrm{I}>, \mathrm{L}, \mathrm{H},>\mathrm{F}]$} & 13 \\
\hline \multirow{10}{*}{ Part 3} & (54) & quasif & $f f$ & quasifff & $f$ & {$[\mathrm{I}<, \mathrm{H},<\mathrm{F}]$} & 6 \\
\hline & (55) & $f f$ & quasiff & $f$ & $f f f$ & {$[\mathrm{I}<, \mathrm{L},<\mathrm{F}]$} & 9 \\
\hline & (56) & $f f$ & $f f f$ & quasifff & quasiff & {$[\mathrm{I}>, \mathrm{H},>\mathrm{F}]$} & 4 \\
\hline & (57) & $f f f$ & $f$ & quasi ff & quasifff & {$[\mathrm{I}>, \mathrm{L},>\mathrm{F}]$} & 7 \\
\hline & $(58)$ & $f f$ & fff & quasifff & quasiff & {$[\mathrm{I}>, \mathrm{H},>\mathrm{F}]$} & 4 \\
\hline & \begin{tabular}{|l}
$(59)$ \\
\end{tabular} & $f f$ & $f$ & quasi ff & $f f f$ & {$[\mathrm{I}<, \mathrm{L},<\mathrm{F}]$} & 9 \\
\hline & $(60)$ & quasiff & $f f f$ & quasi fff & $f$ & {$[\mathrm{I}>, \mathrm{H},>\mathrm{F}]$} & 4 \\
\hline & (61) & $f f f$ & $f f f$ & fff & $f f f$ & {$[\mathrm{I}>,<\mathrm{F}]$} & 2 \\
\hline & $(62)$ & $f f f+f f z$ & $f f f+f f z$ & $f f f+f f z$ & $f f f+f f z$ & {$[\mathrm{I}>,<\mathrm{F}]$} & 2 \\
\hline & (63) & $f f f+f f z$ & $f f f+f f z$ & $f f f+f f z$ & $f f f+f f z$ & {$[\mathrm{I}>,<\mathrm{F}]$} & 2 \\
\hline
\end{tabular}

three types on this left edge appear throughout and distribute almost evenly within Part 2 in the following order: beginning, type 15-dcseg (28); middle, type 14-dcseg (40); and end, type 13-dcsegs (48) and (53). In A- and B-zones of the network (see figure 8), not only do all the original types back in Part 1-1, 3, 4, 7, 9-reoccur in Part 2, two new types 5 and 6 in B-zone are introduced and used frequently. The participations of these two new types in B-zone, along with the three 13,14 , and 15 on the left edge, enclose a small dynamic contour spectrum covering A-, B-, and C-zones in the network (the dashed lines outline this spectrum). On the basis of the outline of this spectrum, we can conclude that Part 2 contains a greater variety of types that project direct, moderately, and fully elaborated contours, creating a significantly more intricate dynamic texture than that of Part 1 . According to the $\mathrm{CT}_{\mathrm{SIM}} \mathrm{s}$ listed on the right side of table 3, more than half of the types map to one another via two- to

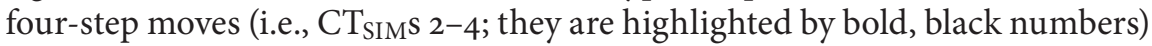
inside this contour spectrum. Comparing these $\mathrm{CT}_{\text {SIM }} \mathrm{S}$ with those in Part 1, a type takes longer distance, more steps to map to another in Part 2 than those in Part 1, which-particularly after dcseg (6) - is composed of types mostly associated by $\mathrm{CT}_{\text {SIMS }} \mathrm{o}$ and 1 . With that said, Crawford uses contours that are more similarly related in Part 1 than those in Part 2. Besides $\mathrm{CT}_{\mathrm{SIM}} \mathrm{S}$ with larger values, the mappings in Part 2 are neither routinely consistent nor easily tractable as those in the previous part. For instance, the triangle-mapping outlined by types 1, 4, 7 in the upper centre of figure 7 disappears in figure 8 . True, while Crawford still writes contours projecting these three types in Part 2, their mappings, nevertheless, do not show any trace of a triangle movement. In fact, type 
Table 2. Dcsegs (1) to (27) and their contour types.

\begin{tabular}{|c|c|c|}
\hline dcsegs & Types & \multirow{7}{*}{ 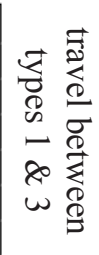 } \\
\hline (1) & 3 & \\
\hline (2) & 1 & \\
\hline (3) & 3 & \\
\hline (4) & 1 & \\
\hline (5) & 1 & \\
\hline (6) & 3 & \\
\hline (7) & 7 & \multirow{21}{*}{ 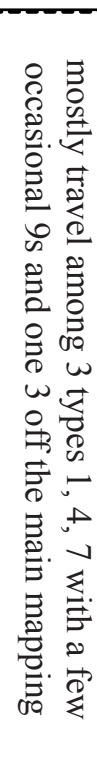 } \\
\hline (8) & 7 & \\
\hline (9) & 4 & \\
\hline (10) & 1 & \\
\hline (11) & 7 & \\
\hline (12) & 4 & \\
\hline (13) & $: * 9$ & \\
\hline (14) & $\begin{array}{l}7 \\
\end{array}$ & \\
\hline (15) & 1 & \\
\hline (16) & * $* 9$ & \\
\hline (17) & $\begin{array}{l}1 \\
\end{array}$ & \\
\hline (18) & $: 9$ & \\
\hline (19) & 4 & \\
\hline (20) & 7 & \\
\hline (21) & 4 & \\
\hline (22) & 4 & \\
\hline (23) & $* 3$ & \\
\hline (24) & 1 & \\
\hline (25) & $* 9$ & \\
\hline (26) & 4 & \\
\hline (27) & 1 & \\
\hline
\end{tabular}

$\square$ traces the mappings marked by $\_$in the network

[-.-.-. traces the mappings marked by - .-- in the network

4 appears only once in Part 2 at dcseg (33), and it is preceded and followed by types 9 and 6 , respectively. Thus, types 1, 4, 7 never occur successively one after another, failing to outline and trace a triangle-mapping.

Finally, while the quartet reaches Part 3 (see figure 9), the mappings return to focus on A- and B-zones by first traveling at the bottom of the network between types 6 and 9 (solid line) and then proceeding to the top between types 4 and 7 (dashed line). ${ }^{17}$ These two mappings both form a one-step move in the network $\left(\mathrm{CT}_{\mathrm{SIM}}=1\right)$, which are parallel to each other. Up to this point in Part 3 , the mappings outlined by solid and dashed lines in the network are easily traceable and routinely consistent, just like those in Part 1. Part 3 is concluded with three dcsegs (61)-(63) projecting the same dynamic contour (thus, their $\mathrm{CT}_{\mathrm{SIM}} \mathrm{S}=\mathrm{o}$ ), which is type 2 located at the centremost spot in the network. If

17 According to table 4, dcsegs (56)-(60) project types 4 and 7 with one exception of 9, which is dcseg (59). 


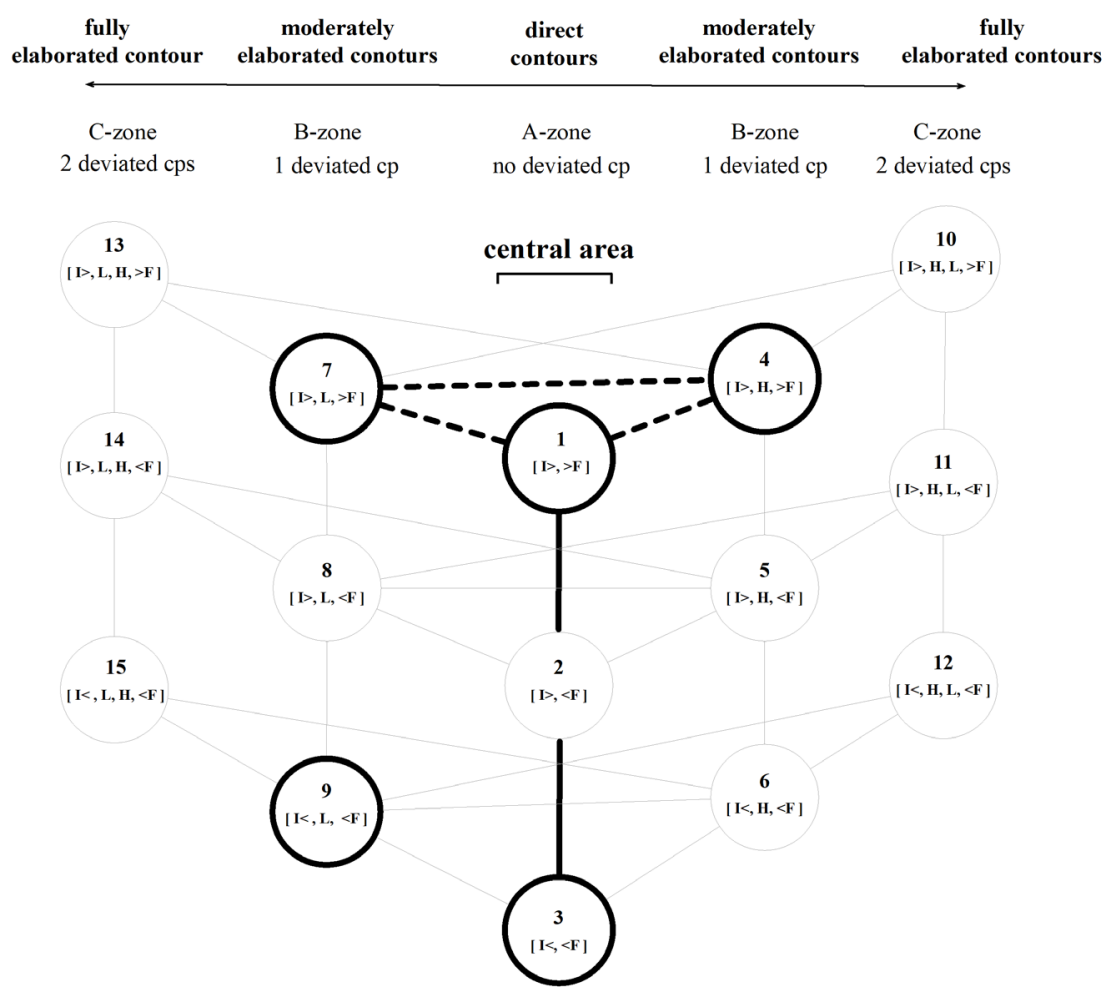

Figure 7. Crawford, String Quartet, Mvt. 3, Part 1; analysis of dcsegs' mappings and their distribution in the network

we revisit the network in figure 7 , the quartet begins with six dcsegs that travel along the central axis by passing through type 2. Its appearance at the very end of Part 3 suggests a unique response to the beginning of the music by filling in the missing part on the central axis, and this design hints at the three-part framework placed on a rounded whole. In addition, the echoing relationship between Parts 1 and 3 can be further extended to include their sharing dynamic texture. Like Part 1, types in Part 3 all come from A- and B-zones, projecting either direct or moderately elaborated contours that create a simple dynamic texture.

Figure 10 summarizes the formal analysis of mm. 1-76. The three-part division is accentuated by (1) the geographical range of dynamic contour type displacements and the overall dynamic texture; while types centre upon A- and B-zones in Parts 1 and 3 and produce a simple dynamic texture, those in Part 2 spread more widely to the edge of the network and produce an intricate dynamic texture; (2) $\mathrm{CT}_{\text {SIM }}$; contour types in Parts 1 and 3 map to one another via smaller moves with $\mathrm{CT}_{\mathrm{SIM}_{\mathrm{M}} \mathrm{S}} \mathrm{O}-1$, and those in Part 2 take longer distance with $\mathrm{CT}_{\mathrm{SIM}} \mathrm{S} 2-4$; and (3) traceable and routine mappings; this feature occurs only in Parts 1 and 3, not in Part 2. These three analytical traits provide the reader with a reference to perceive the formal division of this movement on the 
Table 3. Dcsegs (28) to (53) and their contour types.

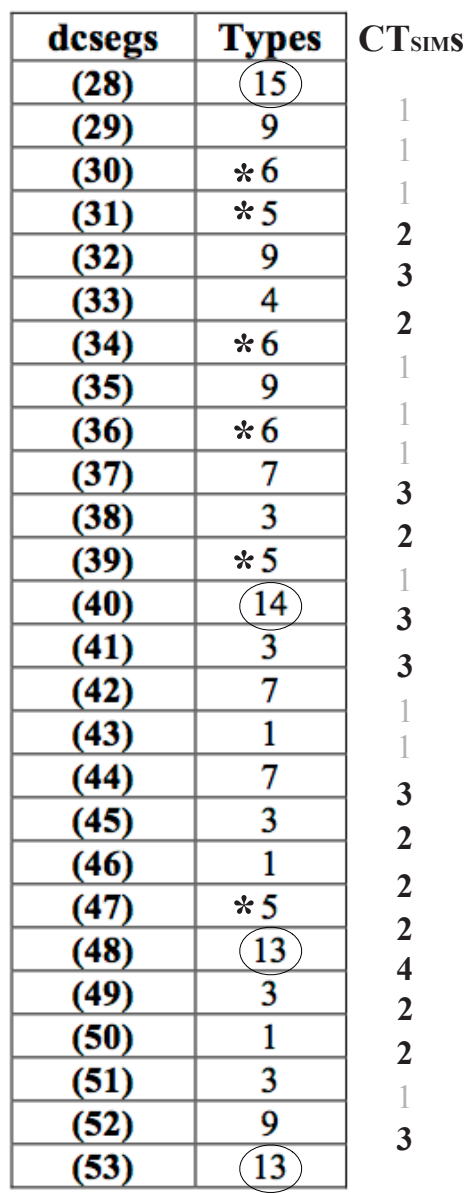

footing of a continual architectural platform narrated by an unfolding span of sound expansion and dynamic contrapuntal texture. Moreover, my findings proposed in figure 10 also beautifully support the three-part formal reading defined by Rao, Nicholls, and Straus. Although each of us has a rather different approach to study this quartet from various contour perspectives of pitch, dynamics, duration, and instrumentations, our findings, nevertheless, are in an agreement that m. 43 and m. 66 are the two decisive moments where the structural formal divisions exactly occur. This reveals an important piece of information about the way Crawford crafts and integrates various musical elements to articulate her formal divisions, creating a coherent three-part form from m. 1 to m. 76 in every respect of her String Quartet, Mvt. 3.

I would like to conclude with a discussion on the ways my analysis can reward our aural experience with this movement. The attentive reader may likely argue, "Can we identify by ear the $\mathrm{CT}_{\text {SIMS }}$ among the verticalized dcsegs within such an exceedingly intricate dynamic contrapuntal texture?" I believe 


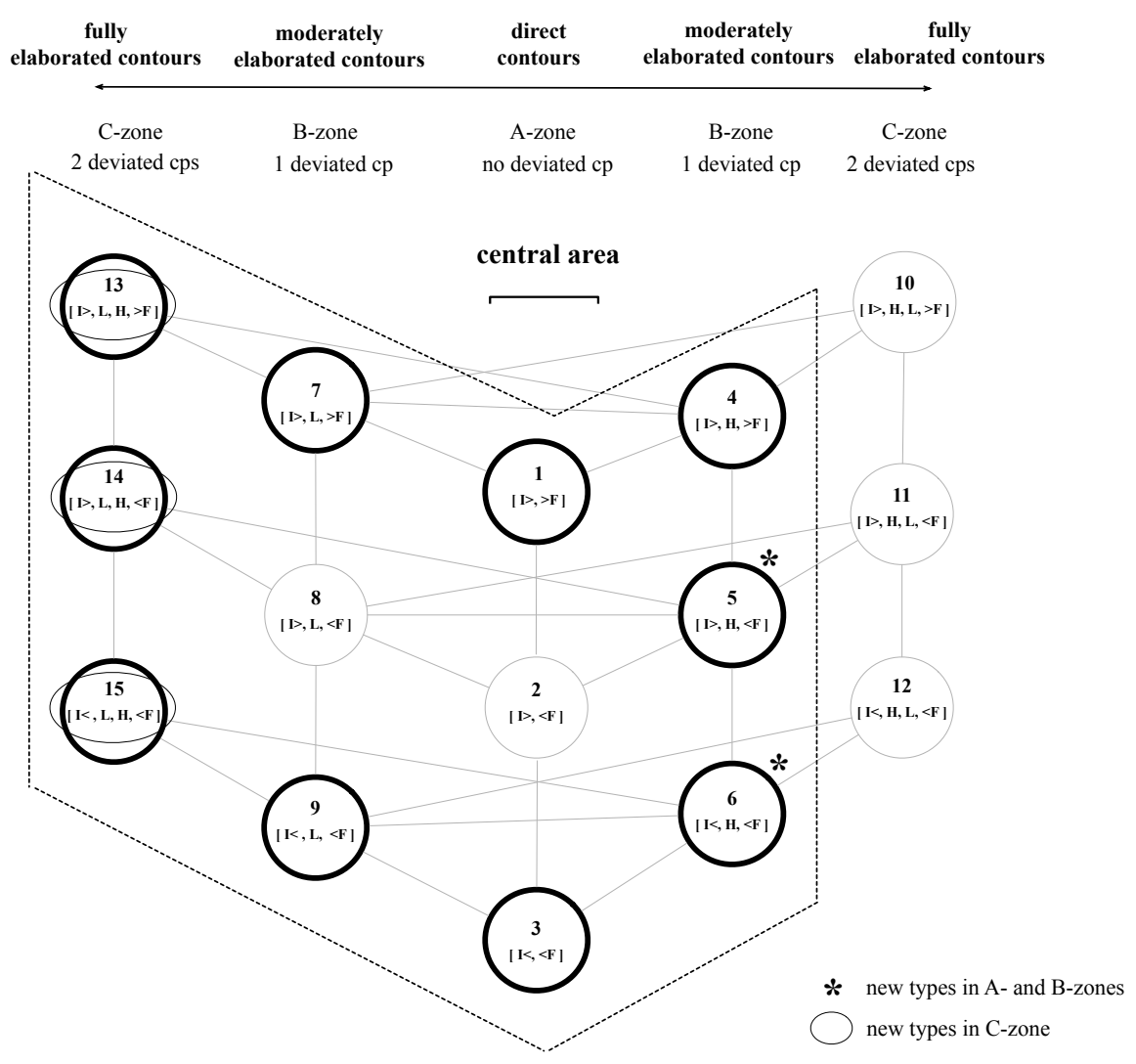

An enclosing contour type spectrum within the network

Figure 8. Crawford, String Quartet, Mvt. 3, Part 2; analysis of dcsegs' mappings and their distribution in the network.

the answer is "Yes." As mentioned previously in the beginning of the analysis, the succession of dcsegs represents the flow of harmonies, in which the adjacent tetrachords differ from one another by the movement of a single pitch, while the remaining ones stay fixed. In this case, our dcsegs articulated by the change of pitch can easily stand out from a maze fabricated by the intricate dynamic counterpoint as opposed to the local, beat-to-beat harmonic progression. The dcsegs thus essentially add clarity to the surface complex texture, for they direct the listener to focus on the moments where the sounds project fuller packages of timbre, dynamics, and the changing pitch. Then, to aurally compare the similarities among different dcsegs, I suggest we begin with playing a few of them slowly on the keyboard and carefully observing how one dcseg is related to another by a certain $\mathrm{CT}_{\text {SIM }}$ based on the results shown in figures 7-9. After several practices, we gain the familiarity of the sound of dcsegs and their $\mathrm{CT}_{\mathrm{SIM}^{-}}$-relationships. Then we can go back to listen to them performed by the quartet and aurally identify the $\mathrm{CT}_{\mathrm{SIM}} \mathrm{S}$ among them. This whole process opens up a new and alternative approach for us to understand harmonies in terms of 
Table 4. Dcsegs (54) to (63) and their contour types.

\begin{tabular}{|c|c|}
\hline dcsegs & Types \\
\hline (54) & 6 \\
\hline (55) & 9 \\
\hline (56) & 4 \\
\hline (57) & 7 \\
\hline (58) & 4 \\
\hline (59) & 9 \\
\hline (60) & 4 \\
\hline (61) & 2 \\
\hline (62) & 2 \\
\hline (63) & 2 \\
\hline
\end{tabular}

traces the mappings marked by

in the network

:---: traces the mappings marked by

-- in the network

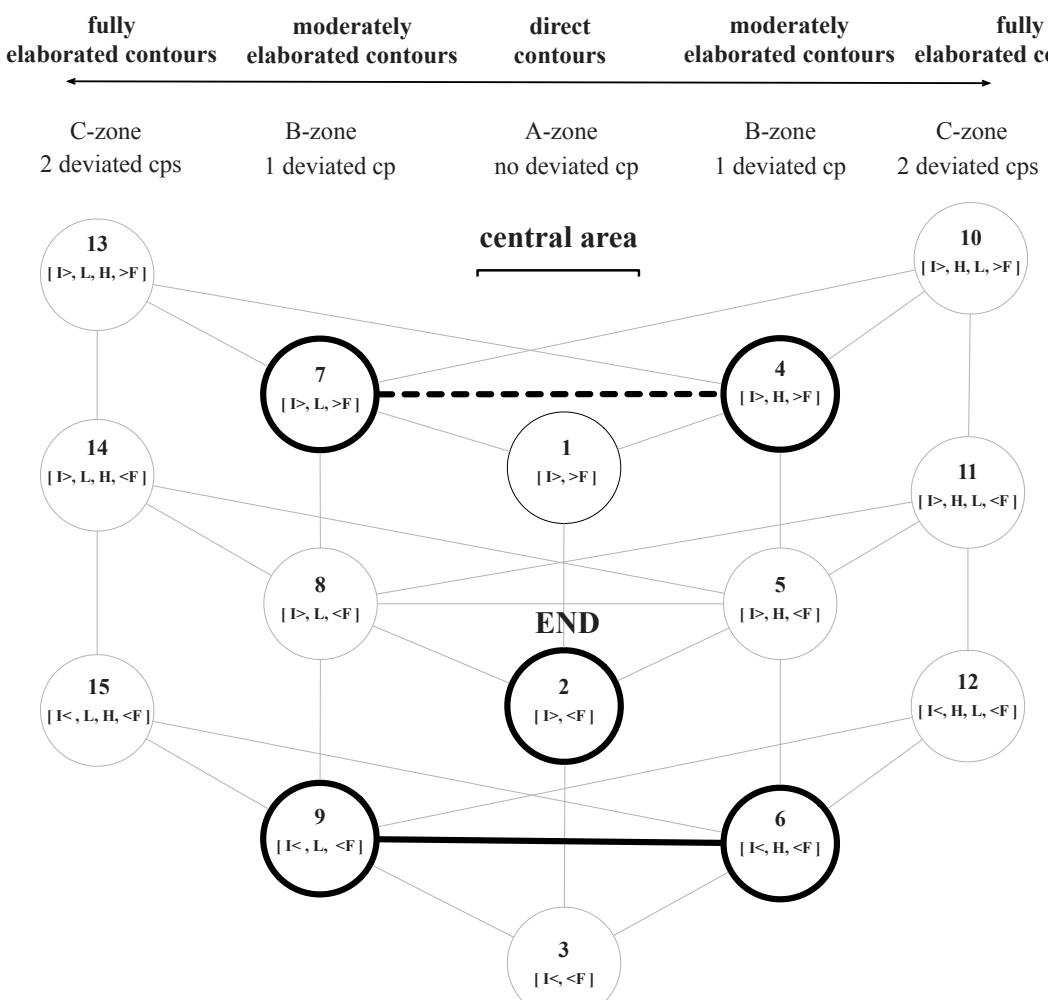

Figure 9. Crawford, String Quartet, Mvt. 3, Part 3; analysis of dcsegs' mappings and their distribution in the network. 


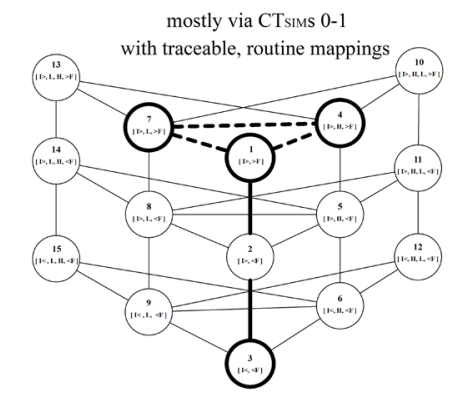

simple dynamic

texture

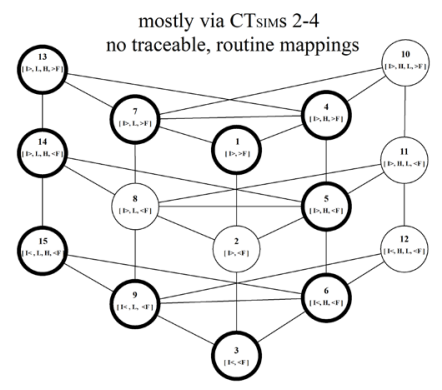

intricate dynamic texture

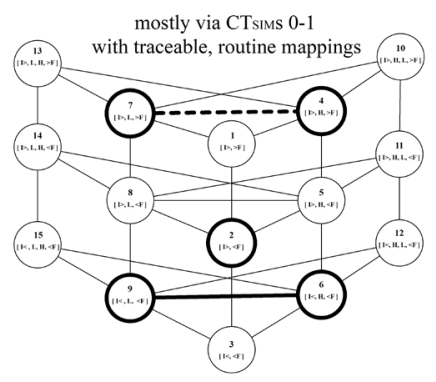

simple dynamic texture

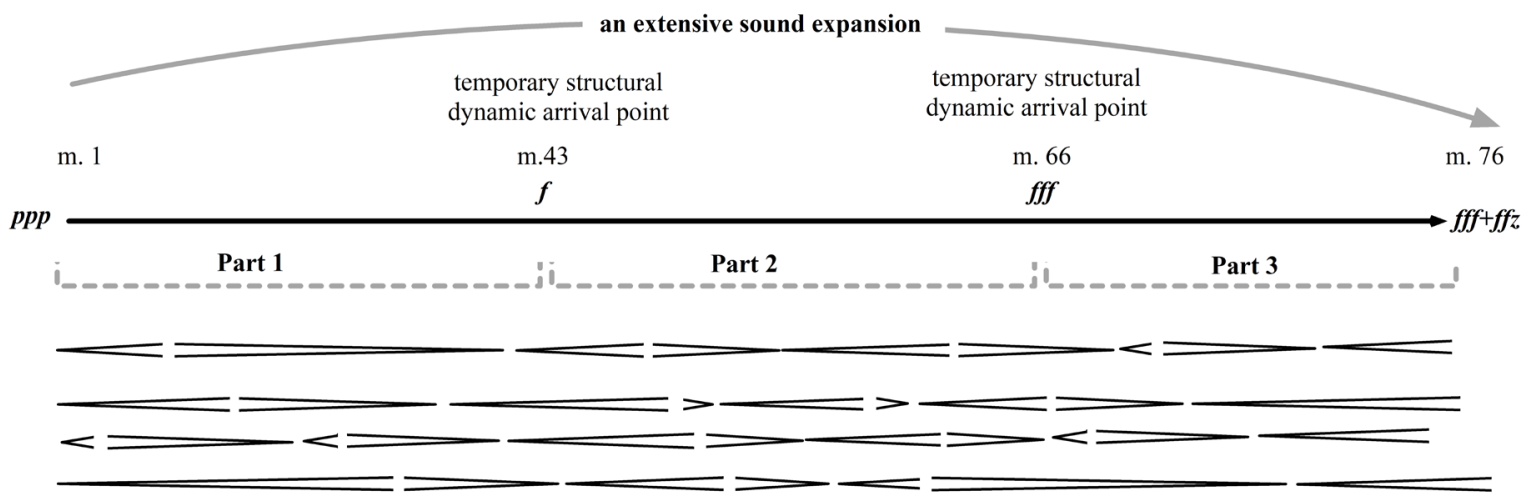

dynamic counterpoint

Figure 10. Ruth Crawford, String Quartet, Mvt. 3, mm. 1-76; analysis of formal division. 
their dcseg-representatives and $\mathrm{CT}_{\text {SIM }}$-relations, which potentially makes both dcseg and $\mathrm{CT}_{\text {SIM }}$ more accessible in Crawford's String Quartet, Mvt. 3.

\section{REFERENCES}

Adams, Charles. 1976. "Melodic Contour Typology." Ethnomusicology 20 (2): 179-215.

Bor, Mustafa. 2009. "Contour Reduction Algorithm: A Theory of Pitch and Duration Hierarchies for Post-Tonal Systems." PhD diss., University of British Columbia.

Carson, Sean. 2004-5. "The Trace, Its Relation to Contour Theory, and an Application to Carter's String Quartet No. 2." Intégral 18/19:113-49.

Carter-Ényí, Aaron. 2016. "Contour Recursion and Auto-Segmentation." Music Theory Online 22 (1). http://www.mtosmt.org/issues/mto.16.22.1/ mto.16.22.1.carter-enyi.html.

Cohn, Richard. 1996. "Maximally Smooth Cycles, Hexatonic Systems, and the Analysis of Late Romantic Triadic Progressions." Music Analysis 15 (1): 9-40.

Friedmann, Michael. 1985. "A Methodology for the Discussion of Contour: Its Application to Schoenberg's Music." Journal of Music Theory 29 (2): 223-48.

_. 1987. "My Contour, Their Contour." Journal of Music Theory 31 (2): $268-74$.

Gaume, Matilda. 1987. Ruth Crawford Seeger: Memoirs, Memories, Music. Metuchen, NJ: Scarecrow, 1987.

Gollin, Edward. 2009. "Form, Transformation and Climax in Ruth Crawford Seeger's String Quartet, Mvmt. 3." Mathematics and Computation in Music 37 (2009): 340-6.

Hannien, Dora. 1996. "A General Theory for Context-Sensitive Music Analysis: Applications to Four Works for Piano by Contemporary American Composers." PhD diss., Eastman School of Music.

_. 2004. "Associative Sets, Categories, and Music Analysis." Journal of Music Theory 48 (2): 147-218.

- 2012. A Theory of Music Analysis: On Segmentation and Associative Organization. Rochester: University of Rochester Press.

Hermann, Richard. 1995. "Theories of Chodal Space, Aspects of Linguistics, and Their Roles in an Analysis of Pitch Structure in Berio's Sequenza IV for Piano." In Concert Music, Rock, and Jazz since 1945, edited by Elizabeth West Marvin and Richard Hermann, 364-98. Rochester, NY: University of Rochester Press.

Hisama, Ellie. 1995. "The Question of Climax in Ruth Crawford's String Quartet, Mvt. 3." In Concert Music, Rock, and Jazz since 1945, edited by Elizabeth West Marvin and Richard Hermann, 285-312. Rochester, NY: University of Rochester Press.

-2001. Gendering Musical Modernism: The Music of Ruth Crawford, Marion Bauer, and Miriam Gideon. Cambridge: Cambridge University Press.

Klein, Michael. 1999. "Texture, Register, and Their Formal Roles in the Music of Witold Lutosławski." Indiana Theory Review 20 (1): 37-70. 
Mailman, Joshua Bank. 2015. "Schoenberg's Chordal Experiment Revealed through Representational Hierarchy Association (RHA), Contour Motives, and Binary State." Music Theory Spectrum 37 (2): 224-52.

Marvin, Elizabeth. 1989. "A Generalized Theory of Musical Contour: Its Application to Melodic and Rhythmic Analysis of Non-Tonal Music and Its Perceptual and Pedagogical Implications." PhD diss., Eastman School of Music.

—. 1991. "The Perception of Rhythm in Non-Tonal Music: Rhythmic Contours in the Music of Edgard Varèse." Music Theory Spectrum 13 (1): 61-78.

— 1995. "A Generalization of Contour Theory to Diverse Musical Spaces: Analytical Applications to the Music of Dallapiccola and Stockhausen." In Concert Music, Rock, and Jazz since 1945, edited by Elizabeth West Marvin and Richard Hermann, 135-71. Rochester, NY: University of Rochester Press, 1995.

Marvin, Elizabeth West, and Paul Laprade. 1987. "Relating Musical Contour: Extensions of a Theory for Contour." Journal of Music Theory 31 (2): 268-74. Morris, Robert. 1987. Composition with Pitch-Classes: A Theory of Compositional Design. New Haven, CT: Yale University Press.

_. 1993. "New Directions in the Theory and Analysis of Musical Contour." Music Theory Spectrum 15 (2): 205-28.

Nicholls, David. 1990. “'On Dissonant Counterpoint': The Development of a New Polyphony, Primarily by Charles Seeger, Carl Ruggles and Ruth Crawford." In American Experimental Music, 1890-1940, 89-133. Cambridge: Cambridge University Press.

Pearsall, Edward. 2012. "Rhythm and Contour." In Twentieth-Century Music Theory and Practice, 163-82. New York: Routledge Taylor \& Francis Group.

Quinn, Ian. 1997. "Fuzzy Extensions to the Theory of Contour." Music Theory Spectrum 19 (2): 232-63.

-1999. "The Combinatorial Model of Pitch Contour." Music Perception 16 (4):439-56.

Rao, Nancy Yunhwa. 2007. "Ruth Crawford's Imprint on Contemporary Composition." In Ruth Crawford Seeger's Worlds: Innovation and Tradition in Twentieth-Century American Music, edited by Ray Allen and Ellie Hisama, 110-47. Rochester, NY: University of Rochester Press.

Schmuckler, Mark. 1999. "Testing Models of Melodic Contour Similarity." Music Perception 16 (3):295-326.

_.2010. "Melodic Contour Similarity Using Folk Melodies." Music Perception 28 (2): 169-83.

Schultz, Robert. 2008. "Melodic Contour and Nonretrogradable Structure in the Birdsong of Oliver Messiaen." Music Theory Spectrum 30 (1): 89-137.

-2009. "A Diachronic-Transformational Theory of Musical Contour Relations." PhD diss., University of Washington.

_. 2016. "Normalizing Musical Contour Theory." Journal of Music Theory $60(1): 23-50$.

Seeger, Charles. 1960. "On the Moods of a Music-Logic." Journal of the American Musicological Society 13 (1-3): 224-61. 
Shmulevich, Ilya. 2004. "A Note on the Pitch Contour Similarity Index." Journal of New Music Research 33 (1): 17-18.

Straus, Joseph. 1987. “The Problem of Prolongation in Post-Tonal Music." Journal of Music Theory 31 (1):1-21.

- 1995. The Music of Ruth Crawford Seeger. Cambridge: Cambridge University Press.

_. 1997. "Voice Leading in Atonal Music." In Music Theory in Concept and Practice, edited by James Baker, David Beach, and Jonathan Bernard, 23774. Rochester, NY: University of Rochester Press.

-2003. "Uniformity, Balance, and Smoothness in Atonal Voice Leading." Music Theory Spectrum 25 (2): 305-52.

_. 2005. "Voice Leading in Set-Class Space." Journal of Music Theory 49 (1): 45-108.

Tick, Judith. 1997. Ruth Crawford Seeger: A Composer's Search for American Music. New York: Oxford University Press.

Wu, Yi-Cheng Daniel. 2012. "Reflection and Representation: A Unitary Theory of Voice Leading and Musical Contour in 2oth-Century Atonal and Serial Contrapuntal Music.” PhD diss., University at Buffalo.

_. 2013. "A New Similarity Measurement of Pitch Contour for Analyzing 2oth- and 21st-Century Music: The Minimally Divergent Contour Network." Indiana Theory Review 31 (1-2): 5-51.

_.2016. "When Quality Reaches Its Limits: A New Interpretative Approach to Understand Post-tonal Music." Musicology Australia 38 (1): 79-107.

— 2019. "An Extension of the Minimally Divergent Contour Network: Considering Nonconsecutive Repeated Contour Pitches." Music Theory Spectrum 41 (2): 341-62.

\begin{abstract}
In the third movement of her String Quartet, locally Ruth Crawford crafts a unique dynamic contrapuntal fabric, where each instrument plays a different alternation of crescendo and diminuendo, thus the same dynamics never synchronize. Globally, this dynamic contrapuntal texture projects an extensively long gradual sound expansion from $p p p$ to $f f$. In addition, Crawford stresses two temporary dynamics $f$ and $f f$, subtly dividing the form into three parts. To support Crawford's subtle formal division, I translate Crawford's dynamic counterpoint into a chronological sequence of verticalized contours and measure their similarity. I find the essential changes in contour similarity always coincide with the structural boundary, sharpening the formal division in Crawford's schematic design.
\end{abstract}

\title{
RÉSUMÉ
}

Dans le troisième mouvement de son Quatuor à cordes, Ruth Crawford élabore localement un tissu contrapuntique dynamique singulier, dans lequel chaque instrument alterne différemment crescendo et diminuendo, les mêmes dynamiques ne se synchronisant ainsi jamais. Globalement, ce tissu contrapuntique dynamique projette une 
très longue expansion sonore graduelle allant de ppp à fff. De surcroit, Crawford met temporairement l'accent sur les deux dynamiques $f$ et $f f$, divisant alors subtilement la forme en trois parties. Afin de soutenir cette subtile division formelle tripartite par Crawford, je traduis son contrepoint dynamique dans les termes d'une séquence chronologique de contours verticalisés, et en mesure la similarité. Je montre ainsi que les changements essentiels de la similarité des contours coïncident toujours avec les limites structurelles, précisant la division formelle de la conception schématique de Crawford.

\section{BIOGRAPHY}

Yi-Cheng Daniel Wu completed his Ph.D. (2012) in Music Theory at the University at Buffalo. His research interests focus on the topics of musical form, harmony, voice leading, and pitch contour in 2oth- and 21st-century music. Prior to coming to Soochow University School of Music (Suzhou, China) in Fall 2013 as the Assistant Professor of Music Theory, he taught at Wesleyan University (Middletown CT, USA), where he served as the Visiting Assistant Professor of Music. His articles appear in Indiana Theory Review, Music Analysis, Musicology Australia, Music Theory Spectrum, and Studia Musicologia. Aside from music theory, he is also interested in piano performance. In the Spring of 2009, he received first prize in the 2008-2009 UBSO Concerto Competition, in which he performed the first movement from Saint-Saëns's Second Piano Concerto. 